\title{
Carcinoma Epidermóide no ouvido médio em gato
}

\author{
Squamous Cell Carcinoma of the middle ear in a cat \\ Heloisa J usten Moreira de Souza ${ }^{1}$, Fernanda Vieira Amorim ${ }^{2}$, Adriana Pereira ${ }^{2}$, Rachel Trani ${ }^{3}$, \\ Raquel Souza Calixto ${ }^{3}$, César Kruger ${ }^{4}$, Ana Maria Reis Ferreira ${ }^{5}$ \& Elan Cardoso Paes de Almeida ${ }^{6}$
}

\begin{abstract}
RESUMO
O carcinoma epidermóide é uma neoplasia maligna localmente invasiva que pode produzir metástases lentas nos linfonodos regionais e metástases distantes tardiamente. Entretanto a localização do carcinoma epidermóide em ouvido médio e/ou ouvido interno é extremamente rara, pois não são áreas expostas à radiação solar. Uma gata, sem raça definida, esterilizada, com três anos de idade apresentava meneios cefálicos para o lado esquerdo e o ouvido do mesmo lado edemaciado e obstruído por secreção purulenta, além de sinais de paralisia do nervo facial e dos ramos simpáticos do tronco simpático cervical do lado esquerdo. O estudo radiográfico do crânio revelou um aumento na densidade do tecido mole dentro da cavidade timpânica e espessamento da bula óssea, com osteólise no osso temporal. Realizou-se uma ablação total do canal auditivo associada a uma osteotomia lateral da bula timpânica e colocação de dreno. O resultado do exame histopatológico do ouvido externo e médio revelou a presença de carcinoma epidermóide bem diferenciado. O prognóstico se tornou reservado devido às características agressivas da neoplasia. O proprietário optou pelo acompanhamento do animal e tratamento de suporte. A gata veio a óbito dois meses depois apresentando sintomatologia neurológica.
\end{abstract}

Descritores: carcinoma epidermóide, ouvido médio, gato.

\section{ABSTRACT}

Squamous cell carcinomas are a locally invasive malignant tumor, with late spread to local lymph nodes and distant metastasis. A 3-year old mixed breed female spayed cat presented head tilt to the left side and edema in the same ear, with blocked external ear canal for purulent discharge. The animal showed signs of paralysis of the facial nerve and cervical sympathetic nerves. The radiographic signs of skull showed increase density of tympanic cavity, temporal osteolysis and the tympanic bula was thick. Surgical treatment was performed through a total canal ablation, lateral bulla osteotomy and placement of a Penrose drain. The histological examination of the external and middle ear diagnosed a well-differentiated squamous cell carcinoma. The prognostic results was reserved because of the aggressive behavior of tumor. The owner of the animal chose to follow the animal with support treatment only. Two months later the animal died with neurological symptoms.

Key words: squamous cell carcinoma, middle ear, cat. 


\section{INTRODUÇÃO}

O carcinoma epidermóide é uma neoplasia maligna localmente invasiva [2,3]. Os gatos brancos, idosos e expostos à radiação solar são os mais acometidos [2]. Normalmente ela ocorre nas regiões da cabeça, especialmente nas pinas, pálpebras e junções mucocutâneas de nariz e boca $[3,8,13]$. Entretanto a localização do carcinoma epidermóide em ouvido médio é extremamente rara, pois não é uma área exposta à radiação solar [3,5].

Inicialmente, os gatos apresentam meneios encefálicos e otorréia purulenta com odor desagradável $[8,13]$. Os sinais sugestivos de comprometimento do ouvido médio são tumefação ou estenose do canal auditivo, paralisia do nervo facial ou Síndrome de Horner [6,11]. No gato, a dor por ocasião da abertura da boca e a presença de disfagia têm sido associadas à neoplasia de ouvido médio [6,10,11].

O diagnóstico de carcinoma epidermóide em ouvido médio se baseia no histórico, anamnese, exame físico, otoscopia, estudos radiográficos e histopatologia, objetivando um diagnóstico definitivo [14].

O diagnóstico diferencial do carcinoma epidermóide no ouvido médio inclui as diversas otopatias de pequenos animais [15].

O tratamento efetivo do carcinoma epidermóide envolve a ressecção cirúrgica, osteotomia da bula lateral com ablação total do canal auditivo, e radioterapia $[3,10]$.

O prognóstico para neoplasias de ouvido médio é sombrio devido a sua malignidade, e porque a sua remoção cirúrgica total é quase que impraticável [3,15]. As complicações pós-operatórias mais comuns são a Síndrome de Horner e a paralisia facial [1,4,7,9, 12,14,16].

O objetivo desse trabalho é relatar um caso de carcinoma epidermóide no ouvido médio em um felino.

\section{RELATO DE CASO}

Um felino, S.R.D., fêmea, esterilizada, com 3 anos de idade, pesando $4,3 \mathrm{~kg}$ e de pelagem tricolor (preta, marrom e amarela) foi encaminhada à Clínica Veterinária Gatos \& Gatos Vet, situada no Rio de Janeiro, apresentando meneios cefálicos para o lado esquerdo e o ouvido do mesmo lado muito edemaciado (Figura 1A). O conduto auditivo encontrava-se obstruído e havia grande quantidade de otorrea purulenta, que era drenada por uma fístula localizada na base da ore- lha. O animal possuía pouca sensibilidade cutânea no lábio superior e na pina esquerda, além de ter perdido o reflexo palpebral do mesmo lado. Por estes motivos, o quadro clínico indicava se tratar de paralisia do nervo facial e dos ramos simpáticos do tronco simpático cervical do lado esquerdo, havendo evolução da infecção para o ouvido médio, A anamnese revelou que o felino possuía otite crônica há 14 meses, não responsiva aos tratamentos convencionais.

Os exames complementares constaram de hemograma completo, exame imunoenzimático para a leucemia e imunodeficiência adquirida felina e estudo radiológico do crânio. A hematimetria revelou anemia regenerativa e o leucograma apresentou leucocitose neutrofílica com desvio nuclear de neutrófilos à esquerda. $\mathrm{O}$ exame imunoenzimático foi negativo. $\mathrm{O}$ estudo radiográfico do crânio nas posições laterais, oblíqua direita e esquerda e na posição rostrocaudal obtida com a gata de boca aberta, revelou um aumento na densidade do tecido mole dentro da cavidade timpânica e espessamento da bula óssea, com osteólise no osso temporal (Figuras 1B e 1C).

Devido às complicações crescentes do quadro clínico do felino, decidiu-se pela resolução cirúrgica do caso, realizando-se uma ablação total do canal auditivo associada a uma osteotomia lateral da bula timpânica e colocação de dreno (Figura 2), com o intuito de se tratar a infecção auditiva e colher material para o exame histopatológico, cultura e antibiograma. A medicação pré-anestésica empregada foi acepromazina ${ }^{1}$, na dosagem de $0,05 \mathrm{mg} / \mathrm{kg}$, tartarato de butorfanol ${ }^{2}$, na dosagem de $0,2 \mathrm{mg} / \mathrm{kg}$ ambos por via IM e flunixin meglumine ${ }^{3}$, na dosagem de $0,5 \mathrm{mg} / \mathrm{kg}$, por via $\mathrm{SC}$. A indução anestésica foi realizada com tiopental ${ }^{4}$, na dosagem de $12,5 \mathrm{mg} / \mathrm{kg}$, por via IV, e a manutenção anestesiológica foi feita com isoflurano ${ }^{5}$.

Macroscopicamente, o canal auditivo se encontrava com bastante fibrose e havia estruturas fétidas e friáveis de aspecto esponjoso ao redor de toda a sua extensão. Foi colocada uma sonda uretral n. 4 e um dreno de Penrose no interior do conduto para facilitar a drenagem do material inflamatório e facilitar sua limpeza. Uma solução de lavagem foi instituída, contendo $95 \mathrm{~mL}$ de soro fisiológico $\mathrm{NaCl}$ a $0,9 \%{ }^{6} \mathrm{e}$ $5 \mathrm{~mL}$ de clorhexidine ${ }^{7}$ a $1 \%$, sendo utilizado $5 \mathrm{~mL}$ desta solução através da sonda, duas vezes ao dia.

No pós-operatório imediato, o animal apresentou Síndrome de Horner, demonstrada por prolapso 

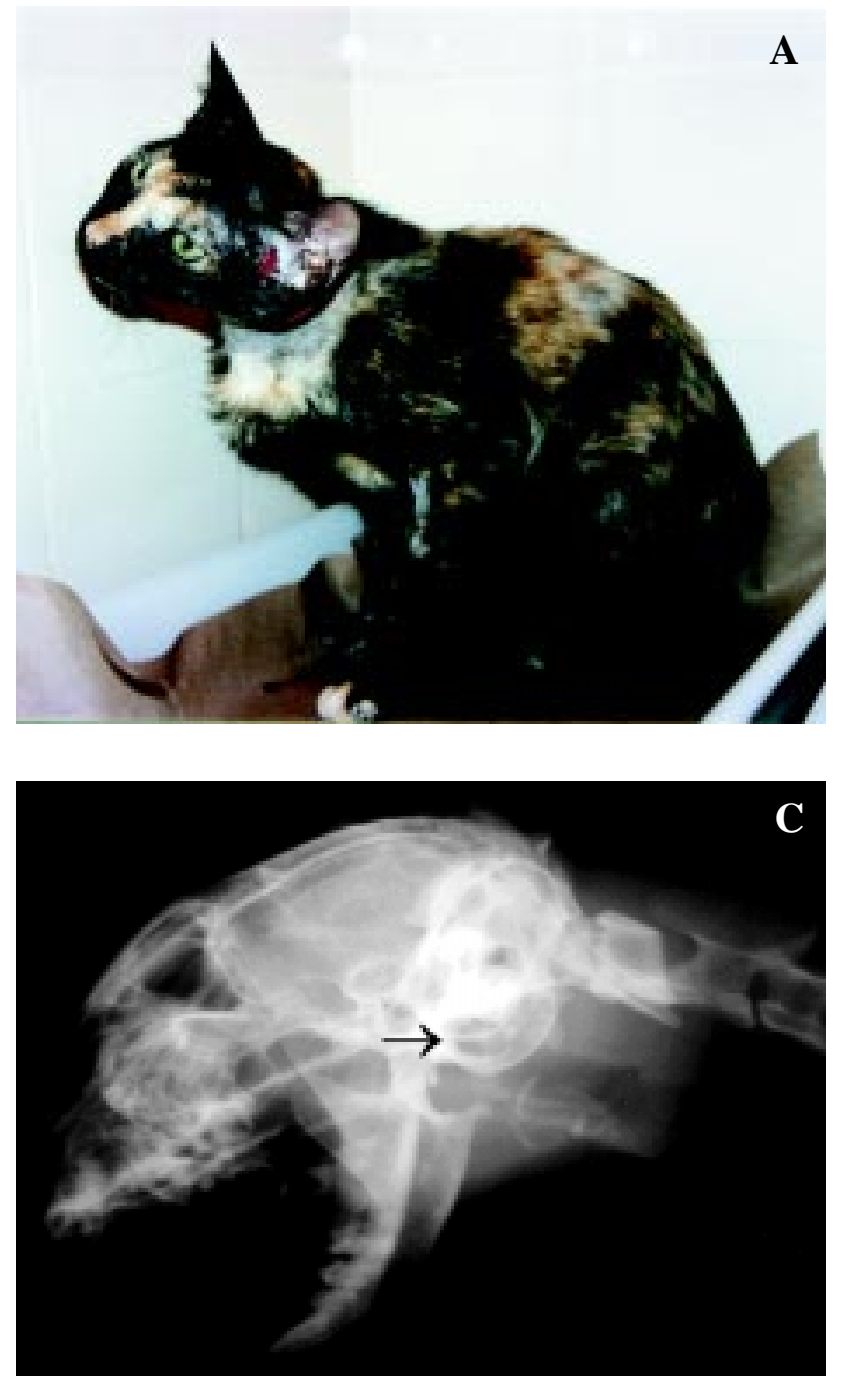

de terceira pálpebra, enoftalmia, miose e ptose da pálpebra superior do olho esquerdo (Figura 3A).

A cultura foi positiva para Staphylococcus aureus e Pseudomonas sp. e um teste de susceptibilidade antimicrobiana foi realizado para orientar o tratamento. A antibioticoterapia instituída foi norfloxacina $^{8}$, na dosagem de $5 \mathrm{mg} / \mathrm{kg}$, por via oral, a cada 12 horas e rifampicina ${ }^{9}$, na dosagem de $20 \mathrm{mg} / \mathrm{kg}$, por via oral, a cada 24 horas.

O resultado do exame histopatológico do ouvido externo e médio revelou a presença de carcinoma epidermóide bem diferenciado, evidenciado por cordões e ninhos de células neoplásicas, com núcleos hipercromáticos e elevada quantidade de pérolas córneas infiltrativas no epitélio epidérmico (Figuras 4B e 4C).

O prognóstico se tornou reservado devido às características agressivas da neoplasia. O proprietário optou pelo acompanhamento do animal e tratamento

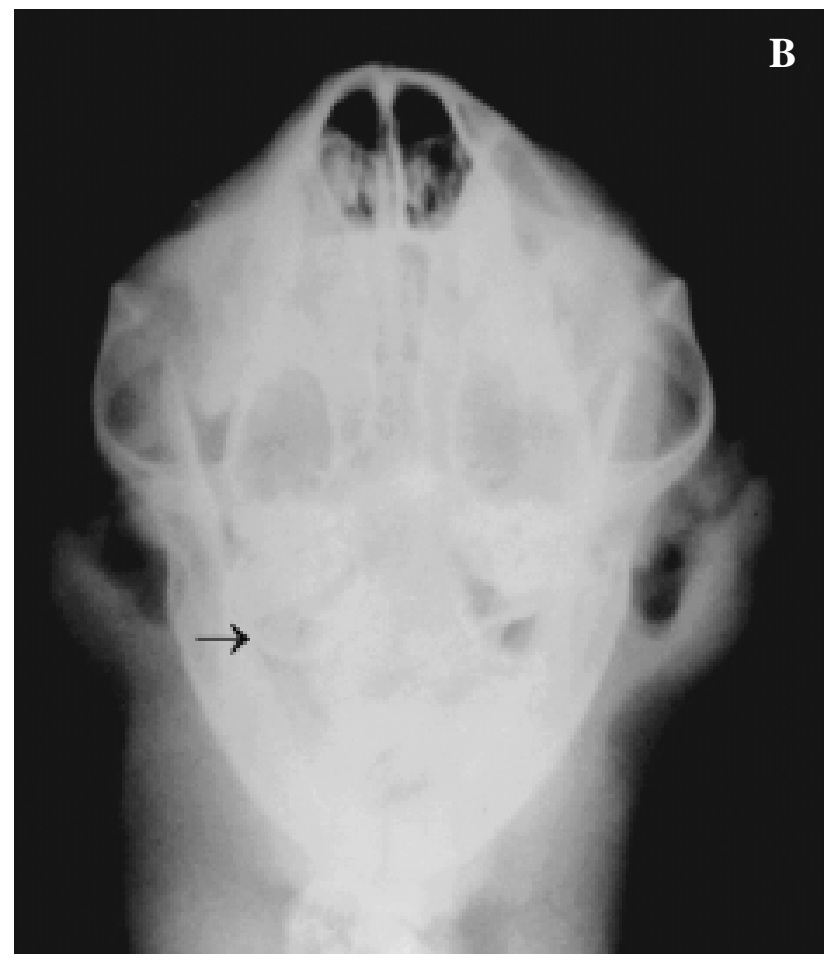

Figura 1. [A] Gata apresentando inclinação e meneio cefálico para o lado esquerdo. Notar lesões ulcerativas na pele, próxima ao pavilhão auricular. [B] Estudo radiológico do crânio. Posição rostrocaudal obtida com o felino de boca aberta. Aumento na densidade do tecido mole dentro da cavidade timpânica. [C] Estudo radiológico do crânio. Posição lateral oblíqua direita. Espessamento da bula óssea, com osteólise no osso temporal. (créditos Heloisa Justen).

de suporte. A gata veio a óbito dois meses depois, apresentando sintomas neurológicos, sugerindo evolução da neoplasia para o ouvido interno.

\section{DISCUSSÃO}

O carcinoma epidermóide é o tumor cutâneo maligno mais comum nos felinos [10]. Ele é encontrado com maior frequiência na pele despigmentada ou pouco pigmentada, por possuir uma estreita relação com a exposição aos raios ultravioletas, sendo também chamado de tumor actínico [6,8]. A incidência do carcinoma epidermóide é maior em animais mais idosos $[5,6,8,13,14,16]$, de pelagem branca e com exposição à luz solar no local da afecção [10]. No caso ora descrito o animal era jovem, com apenas três anos, sua pelagem era tricolor; e não havia incidência de luz solar na localização do tumor $[5,6,8,13,14,16]$.

No presente trabalho, os sintomas mais evidentes da otite crônica provocada pelo carcinoma epi- 


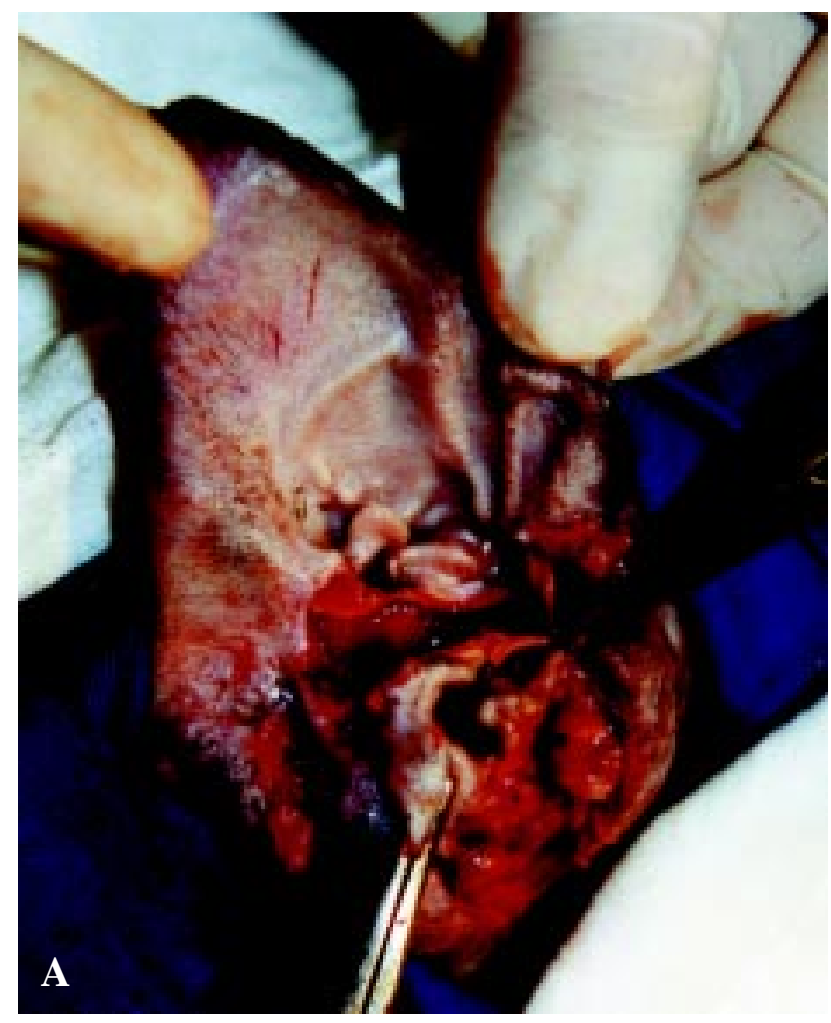

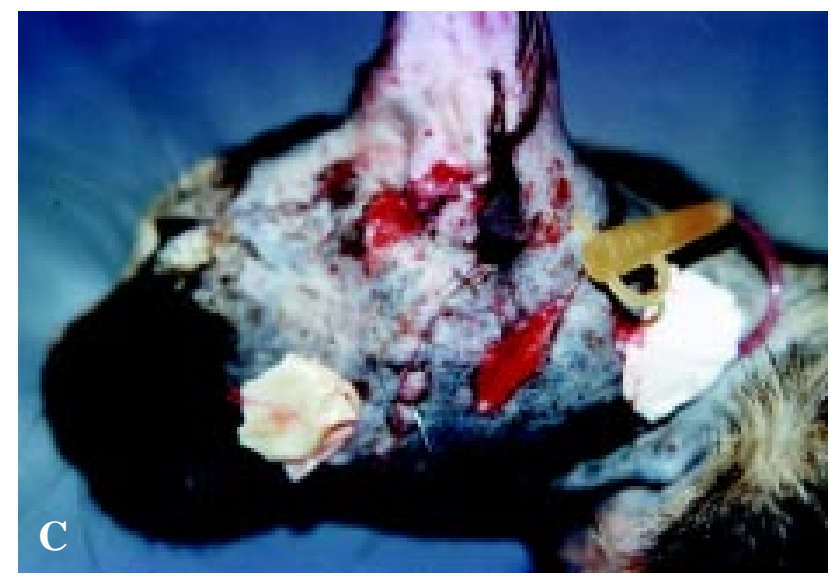

dermóide no ouvido médio foram obstrução total do conduto auditivo externo esquerdo com otorrea purulenta e edema de ouvido esquerdo, inclinação da cabeça para o lado esquerdo, sinais clínicos de paralisia do nervo facial esquerdo como insensibilidade cutânea do lábio superior e da pina esquerda, perda do reflexo palpebral esquerdo [13,14] e dor ao abrir a boca $[8,14]$. A infecção bacteriana ocorreu provavelmente devido à otite causada pela presença física do tumor.

Os epitélios de superfície do ouvido interno, ouvido médio, tuba de eustáquio, orofaringe, seios nasais e paranasais e epitélio de revestimento dos ductos salivares são similares $[5,6,8]$. Por este motivo, não foi possível esclarecer a origem do carcinoma neste caso, já

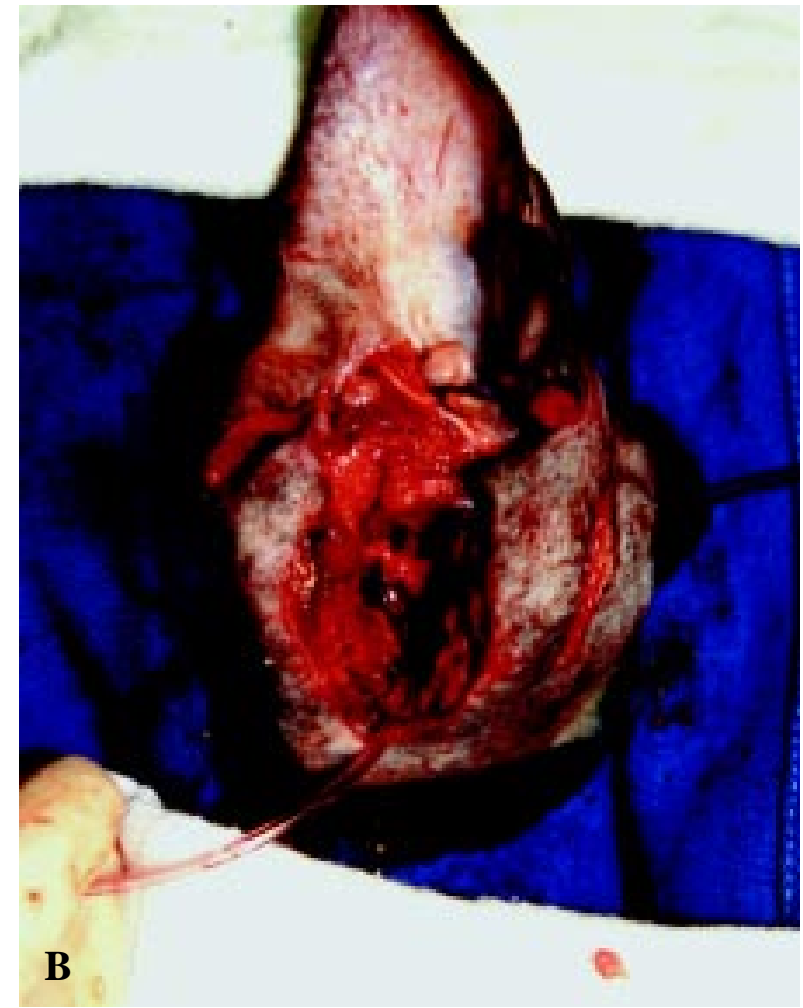

Figura 2. [A] Ablação total do canal auditivo associado à osteotomia lateral da bula timpânica esquerda. [B] e [C] Colocação de dreno de Penrose e sonda uretral para viabilizar a irrigação da ferida. (créditos Heloisa Justen).

que a neoplasia poderia se originar de qualquer um destes epitélios.

O estudo radiográfico do crânio e o exame histopatológico foram essenciais para confirmar o diagnóstico. No estudo radiográfico do crânio nas posições laterais, oblíqua direita e esquerda foram visualizadas as bulas timpânicas individualmente e, na posição rostrocaudal obtida com o felino de boca aberta, visualizou-se as duas bulas timpânicas. Observou-se que existia um aumento na densidade do tecido mole dentro da cavidade timpânica e espessamento da bula óssea, além de osteólise no osso temporal, evidenciando o comprometimento da bula timpânica esquerda $[5,8,13,14]$. A presença de lise e/ou reação periostal da 

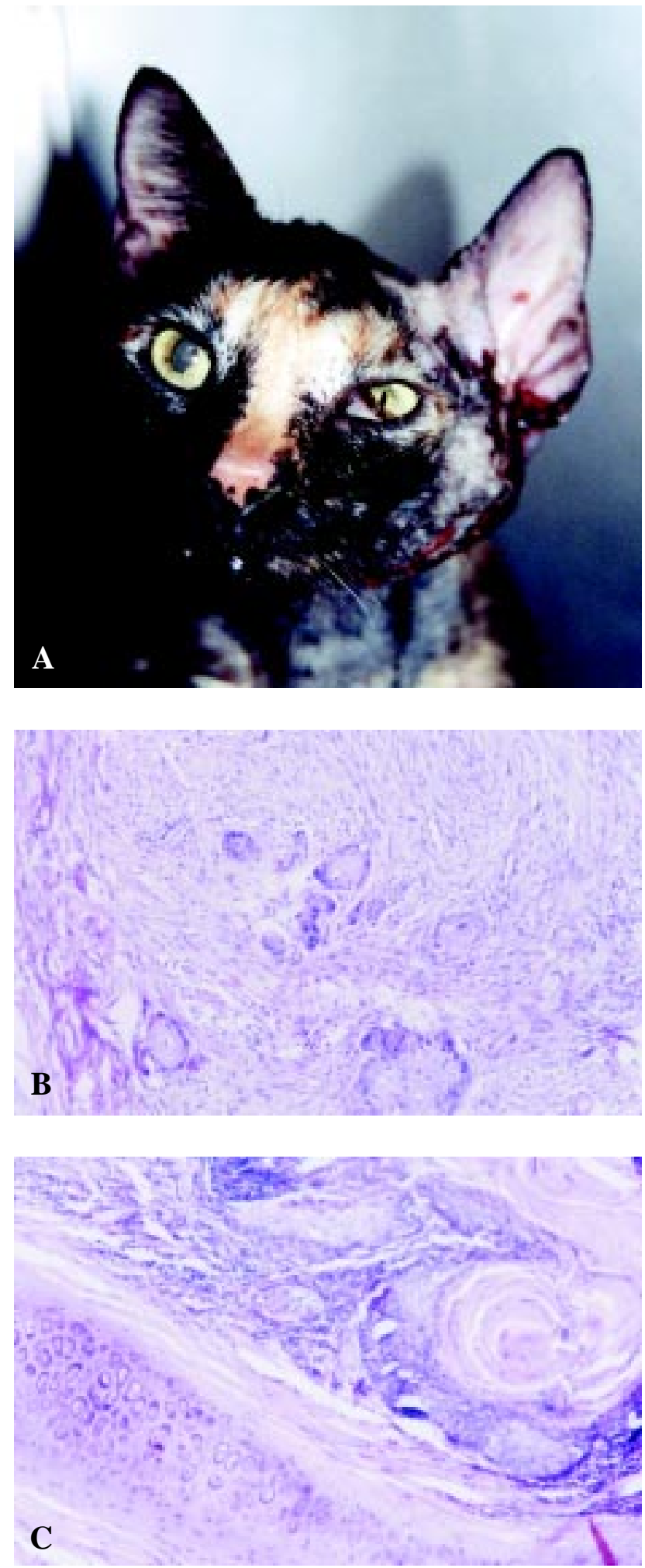

Figura 3. [A] Pós-operatório imediato: Síndrome de Horner. (créditos Heloisa Justen). [B] Fotomicrografia de carcinoma epider-móide bem diferenciado de ouvido médio. Cordões e ninhos de células neoplásicas, com núcleo hipercromático. H\&E (100x). (créditos Fernanda Amorim). [C] Fotomicrografia de carcinoma epidermóide bem diferenciado de ouvido médio. Infiltrado infla-matório, células neoplásicas e pérola córnea, adjacente à cartilagem do ouvido. $\mathrm{H} \& \mathrm{E}(40 \mathrm{x})$. (créditos Fernanda Amorim). bula e da parte petrosa do osso temporal aumentam a suspeita de neoplasia [14].

No presente caso, o felino foi submetido a uma intervenção cirúrgica onde foi realizada a ablação total do canal auditivo esquerdo associada a uma osteotomia lateral da bula timpânica esquerda [10], com o intuito de se tratar a infecção auditiva e colher material para o exame histopatológico, cultura e antibiograma.

O estudo radiográfico do crânio concomitantemente com a confirmação do diagnóstico pela avaliação histopatológica são importantes na exclusão dos diagnósticos diferenciais como otite média bacteriana, outras neoplasias de ouvido médio e pólipos inflamatórios (principalmente em animais jovens) [15]. Mesmo assim, o exame da orofaringe não deve ser descartado, pois há relatos de carcinoma epidermóide na cavidade oral [6].

O tratamento para o carcinoma epidermóide na orofaringe é cirúrgico, associado aos protocolos quimioterápicos [3,10]. Entretanto, no presente caso a neoplasia ocorreu no ouvido médio, não havendo relatos de eficácia da quimioterapia [2,5]. É de supor que pela semelhança do epitélio do conduto auditivo com o epitélio da cavidade oral, o protocolo quimioterápico para o tumor localizado na orofaringe possa ter algum efeito no carcinoma epidermóide localizado no conduto auditivo. Sendo assim, existe a necessidade de se realizar outros estudos nestes casos.

No pós-operatório imediato foi observada a Síndrome de Horner por compressão do plexo simpático no promontório na cavidade do ouvido médio, decorrente do trauma realizado durante a curetagem da bula timpânica esquerda $[8,14,16]$. Os sinais demonstrados pelo animal foram prolapso de terceira pálpebra, enoftalmia, miose e ptose da pálpebra superior do olho esquerdo.

No caso relatado o prognóstico foi desfavorável. $\mathrm{O}$ animal obteve piora clínica significativa após dois meses da intervenção cirúrgica apresentando sintomas neurológicos, o que sugere neoplasia no ouvido interno, com disfunção vestibular [6,8,13,14], sendo indicado eutanásia do animal [6,14].

Conclui-se que o carcinoma epidermóide deve ser incluído no diagnóstico diferencial de afecções do ouvido médio. É necessário realizar-se o diagnóstico definitivo dessa grave doença do ouvido médio através da avaliação histopatológica, pois se trata de uma 
Souza H.J.M., Amorim F.V., Pereira A., Trani R., Calixto R.S., Kruger C., Ferreira A.M.R. \& Almeida E.C.P. 2005. Carcinoma Epidermóide no ouvido médio em gato. Acta Scientiae Veterinariae. 33:329-334.

neoplasia localmente invasiva com resposta pobre as modalidades terapêuticas convencionais e de prognóstico desfavorável.

\section{NOTAS INFORMATIVAS}

${ }^{1}$ Acepram ${ }^{\circledR}$, Univet S/A Indústria Veterinária - São Paulo, SP/ Brasil.

${ }^{2}$ Torbugesic ${ }^{\circledR}$, Fort Dodge Saúde Animal Ltda - Campinas, SP/Brasil
${ }^{3}$ Banamine ${ }^{\circledR}$, Schering-Plough Veterinária - São Paulo, SP/ Brasil.

${ }^{4}$ Thionembutal ${ }^{\circledR}$, ABBOT - São Paulo, SP/Brasil.

${ }^{5}$ Isoflurane ${ }^{\circledR}$, Cristália - Rio de Janeiro, RJ/Brasil.

${ }^{6}$ Fisiológico Cloreto de sódio $0,9 \%{ }^{\circledR}$, J.P. Indústria farmacêutica - Ribeirão Preto, SP/Brasil.

${ }^{7}$ Merthiolate ${ }^{\circledR}$ - solução tópica a $1 \%$, DM Indústria Farmacêutica - Barueri, SP/Brasil.

${ }^{8}$ Norfloxacina ${ }^{\circledR}$, Sanval - São Paulo, SP/Brasil.

${ }^{9}$ Rifamp ${ }^{\circledR}$, Neo-Química - Anápolis, GO/Brasil.

\section{REFERÊNCIAS}

1 Beckman S.L., Henry Jr. W.B. \& Cechner P. 1990. Total ear canal ablation combining bulla osteotomy and curettage in dogs with chronic otitis externa and media. Journal of the American Veterinary Medical Association. 196: 84-90.

2 Couto C.G. \& Hammer A.S. 1994. Oncology. In: Sherding R.G. (Ed). The Cat: Diseases and Clinical Management. Philadelphia: W.B. Saunders, pp.755-818.

3 Cox C. 1990. Surgical management of inflammatory and neoplastic conditions affecting the cat's ear. Veterinary Annual. 30 : 309-314.

4 Devitt C.M., Seim H.B., Willer R., McPherron M. \& Neely M. 1997. Passive Drainage Versus Primary Closure After Total Ear Canal Ablation- Lateral Bulla Osteotomy in Dogs: 59 Dogs (1985-1995). Veterinary Surgery. 26: 210-216.

5 Diniz P.P.V.P., Gerardi D.G.,Aptekmann K.P., Canola J.C., Costa M.T. \& Santana A.E. 2002. Hemiparalisia facial em felino com carcinoma de células escamosas em bula timpânica. In: Anais do XXIII Congresso Brasileiro de Clínicos Veterinários e Pequenos Animais (Brasília, Brasil). p.117.

6 Fiorito D.A. 1986. Oral and peripheral vestibular signs in a cat with squamous cell carcinoma. Journal of the American Veterinary Medical Association. 188: 71-72.

7 Henry Jr. W.B. 1996. Ouvido Médio. In: Bojrab M.J. (Ed). Técnicas atuais em cirurgia de pequenos animais. 3.ed. São Paulo: Roca, pp.141-143.

8 Indrieri R.J. 1984. Vestibular dysfunction caused by squamous cell carcinoma involving the middle ear and inner ear in two cats. Journal of the American Veterinary Medical Association. 184: 471-473.

9 Krahwinkel D.J., Pardo A.D., Sims M.H. \& Bubb W.J. 1993. Effect of total ablation of the external acoustic meatus and bulla osteotomy on auditory function in dogs. Journal of the American Veterinary Medical Association. 202: 949-952.

10 Moore A.S. \& Ogilvie G.K. 2001. Tumors in ears. In: Ogilvie G.K. \& Moore A.S. (Eds). Feline Oncology: A comprehensive guide to compassionate care. Trenton: Veterinary Learning Systems, pp.260-263.

11 Rosychuk R.A.W. \& Luttgem P.J. 1997. Olhos, Ouvidos, Focinho e Garganta. In: Ettinger, S.J. (Ed). Tratado de Medicina Interna Veterinária. 4.ed. São Paulo: Manole, pp.774-785.

12 Seim III H.B. 1993. Middle Ear. In: Slatter D. (Ed). Textbook of Small Animal Surgery. 2nd edn. Philadelphia: W.B. Saunders, pp.1568-1576.

13 Stone E.A., Goldschmidt M.H. \& Littman M.P. 1983. Squamous cell carcinoma of the middle ear in a cat. Journal of Small Animal Practice. 24: 647-651.

14 Trevor P.B. \& Martin R.A. 1993. Tympanic bulla osteotomy for treatment of middle- ear disease in cats: 19 cases (19841991). Journal of the American Veterinary Medical Association. 202: 123-128.

15 Venker-van Haagen A.J. 1994. Diseases and Surgery of the Ear. In: Sherding R.G. (Ed). The Cat: diseases and clinical management. New York: Churchill Linvingstone, pp.1999-2009.

16 Williams J.M. \& White R.A.S. 1992. Total ear canal ablation combined with lateral bulla osteotomy in the cat. Journal of Small Animal Practice. 33: 225-227.

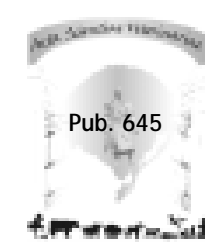

